\title{
Reduced Port Laparoscopic Surgery for Rectal Cancer
}

\author{
Byung Chun Kim \\ Department of Surgery, Hallym University Kangnam Sacred Heart Hospital, Hallym University College of Medicine, Seoul, Korea
}

See Article on Page 16-22

Due to the significant improvement in minimal invasive surgery, a large group of surgeons has focused on cosmetic results and minimization of the number and the size of the ports. In addition, a single-incision laparoscopic colectomy was recently introduced to reduce patient's trauma related with conventional multiport approaches. In a single-incision laparoscopic colectomy, all trocars are inserted through one umbilical incision. However, published studies are limited, for the most part, to the right colon [1] and the sigmoid colon [2], and single-incision laparoscopic surgery in the field of rectal surgery is very rare [3] because of the difficulties in many cases in securing the surgeon's operative field [4]. One study reported that the rectum was vertically lifted by using a suspension bar to obtain the operative field [4]. Transecting the lower rectum via an umbilical port and securing a sufficient distal margin is very challenging because of the technical limitation that the tip of the laparoscopic stapler can be bent only 45 degrees. Numerous studies of single-incision laparoscopic rectal surgery in which multiple staplers were used for making an incision have reported that the chance of anastomotic leakage was decreased when the number of linear stapler used in lower rectum transection was reduced $[5,6]$. Pelvic drainage after rectal surgery is required for the early detection of anastomotic leakage and to avoid reoperation. A single incision site after the rectal incision can be used as an incision for drainage in reduced port laparoscopic rectal surgery.

In this study, the authors performed reduced port laparoscopic surgery on 20 colorectal cancer patients by using an umbilical port

Correspondence to: Byung Chun Kim, M.D.

Department of Surgery, Hallym University Kangnam Sacred Heart Hospital, Hallym University College of Medicine, 1 Singil-ro, Yeongdeungpo-gu, Seoul 150-950, Korea

Tel: +82-2-829-5130, Fax: +82-2-849-4469

E-mail: bckimgs@hallym.or.kr

(C) 2015 The Korean Society of Coloproctology

This is an open-access article distributed under the terms of the Creative Commons Attribution NonCommercial License (http://creativecommons.org/licenses/by-nc/3.0) which permits unrestricted noncommercial use, distribution, and reproduction in any medium, provided the original work is properly cited. and an additional port in the right lower quadrant. The operation time (231 minutes), blood loss (100 mL), number of staplers, days to first soft diet, length of hospital stay, number of lymph nodes harvested, circumferential resection margin involvement, complications, and the rates of local recurrence and distant metastasis were comparable to those reported in other studies. However, the authors stated that further studies were needed to confirm the benefits of the procedure [7].

A reduced port procedure allows surgeons to secure a distal resection margin and is an easier surgical procedure for treating patients with low rectal cancer than procedures using only an umbilical port. Furthermore, that the incision can be utilized for pelvic drainage for a safer operation is worth mentioning. For the validation of the advantages of such procedures, further multicenter and comparative studies are demanded.

\section{CONFLICT OF INTEREST}

No potential conflict of interest relevant to this article was reported.

\section{REFERENCES}

1. Choi SI, Lee KY, Park SJ, Lee SH. Single port laparoscopic right hemicolectomy with D3 dissection for advanced colon cancer. World J Gastroenterol 2010;16:275-8.

2. Takemasa I, Sekimoto M, Ikeda M, Mizushima T, Yamamoto H, Doki Y, et al. Video. Transumbilical single-incision laparoscopic surgery for sigmoid colon cancer. Surg Endosc 2010;24:2321.

3. Bulut O, Nielsen CB. Single-incision laparoscopic low anterior resection for rectal cancer. Int J Colorectal Dis 2010;25:1261-3.

4. Uematsu D, Akiyama G, Narita M, Magishi A. Single-access laparoscopic low anterior resection with vertical suspension of the rectum. Dis Colon Rectum 2011;54:632-7.

5. Hamzaoglu I, Karahasanoglu T, Baca B, Karatas A, Aytac E, Kahya AS. Single-port laparoscopic sphincter-saving mesorectal excision for rectal cancer: report of the first 4 human cases. Arch Surg 2011;146:75-81.

6. Kim JS, Cho SY, Min BS, Kim NK. Risk factors for anastomotic leakage after laparoscopic intracorporeal colorectal anastomosis 


\section{Coloproctology}

with a double stapling technique. J Am Coll Surg 2009;209:694701.

7. Bae SU, Baek SJ, Min BS, Baik SH, Kim NK, Hur H. Reduced- port laparoscopic surgery for a tumor-specific mesorectal excision in patients with colorectal cancer: initial experience with 20 consecutive cases. Ann Coloproctol 2015;31:16-22. 